\title{
A expressão conectiva na verdade: contribuições para uma abordagem polifônica dos conectores reformulativos
}

\author{
The expression connective na verdade: contributions to a polyphonic \\ approach of reformulative connectors
}

\author{
Gustavo Ximenes Cunha \\ Janice Helena Chaves Marinho
}

Universidade Federal de Minas Gerais -UFMG- Minas Gerais- Brasil

\begin{abstract}
Resumo:Neste trabalho, partimos de estudos que analisaram o papel conectivo da expressão na verdade, para mostrar que essa expressão tem atuação importante na maneira como o locutor representa, em seu discurso, outros discursos ou outras vozes. Adotando o Modelo de Análise Modular do Discurso como referencial teórico e metodológico, estudamos o papel de na verdade na forma de organização polifônica de um artigo de opinião e de um debate eleitoral. Como resultados, temos que a expressão pode funcionar como marca de discurso implicitado polifônico, quando o locutor retoma discursos com origem na voz de personagens, e como marca de discurso implicitado diafônico, quando o locutor retoma discursos com origem na voz do interlocutor. Como marca de discurso implicitado polifônico, na verdade reforça informações dadas previamente, com o fim de conquistar a adesão do leitor ou ouvinte. Mas, como marca de discurso implicitado diafônico, a mesma expressão funciona como um recurso para atacar, rejeitar ou colocar sob suspeita o discurso do interlocutor.
\end{abstract}

Palavras-chave:Na verdade. Discurso implicitado. Polifonia.

Abstract: In this paper, we start from studies examining the role of the connective expression naverdade in order to show that this expression has an important performance in the way the speaker represents, in his speech, other speeches or other voices. Adopting the Geneva Model of discourse analysis as theoretical and methodological framework, we study the role of this expression in the polyphonic organization form of an opinion article and an election debate. As a result, this expression can function as a polyphonic implicit speech mark when the speaker retakes talks with origin in characters' voice and also as a diaphonic implicit speech mark when the speaker retakes talks with origin in the interlocutor's voice. As a polyphonic implicit speech mark, naverdade reinforces information given previously, in order to gain the reader's accession. But as a diaphonic implicit speech mark, the same expression works as a resource to attack, to reject or to impugn the interlocutor's speech.

Keywords: Na verdade. Implicit speech.Polyphony. 


\section{Introdução}

Partindo dos estudos de Ducrot sobre a natureza polifônica de conectores como mais (1980, 1987), Roulet (1997, 1999, ROULET et al, 1985) evidencia o importante papel que o conector em início de réplica pode exercer na organização polifônica de uma produção discursiva, se, com esse conector, o locutor articula o discurso que produz ao discurso produzido previamente pelo interlocutor, em trocas como esta:

A: Prometo que vamos ao cinema no próximo final de semana.

B: Mas você só promete. Não acredito mais em você!

Na segunda intervenção, B usa o conector mas para articular seu ponto de vista ao ponto de vista expresso por A. Em outros termos, por meio de um conector, B retoma de forma implícita o discurso produzido pelo interlocutor. Por isso, o conector mas, nesse exemplo, funciona como marca de discurso implicitado. Conforme Roulet, esse uso dos conectores costuma ocorrer em contextos de maior agressividade entre os interlocutores, por ser bastante hostil para a face do interlocutor. Afinal, como exemplifica a troca acima, por meio de sua intervenção, B nega a sinceridade de $\mathrm{A}$ ao fazer a promessa.

Tomando como ponto de partida estudos sobre - papel conectivo da expressão na verdade (MENDES, 2015, MARINHO, 2016), este trabalho defende a hipótese de que essa expressão conectiva, assim como o mas no exemplo anterior, pode ser empregada como marca de discurso implicitado. Para estudar esse emprego de na verdade, este trabalho se vale de contribuições teóricas e metodológicas do Modelo de Análise Modular do Discurso (ROULET, 1999, ROULET, FILLIETTAZ, GROBET, 2001, MARINHO, 2004).

O Modelo de Análise Modular (MAM) desenvolveu-se, na Universidade de Genebra, sob a liderança de Eddy Roulet, com a proposta de ser um instrumento de análise eficaz para uma abordagem interacionista da complexidade da organização do discurso. Alinhado às propostas de Bakhtin, o MAM concebe o discurso como um processo de negociação discursiva para o qual convergem informações linguísticas, textuais e situacionais. O MAM consiste num instrumento de análise de discursos, visto que oferece um quadro teóricometodológico que permite a descrição e a explicação dos diferentes aspectos da constituição e da articulação do discurso.

Nessa abordagem, trabalha-se com a hipótese de que um objeto complexo, como é o discurso, pode (e deve) ser decomposto num certo número de sistemas de informações simples e autônomos (módulos), que podem ser descritos inicialmente de maneira independente, ou seja, sem referência a outros sistemas de informações. No MAM, considerase que cada dimensão do discurso (linguística, textual e situacional) se constitui de módulos. A dimensão linguística se constitui dos módulos lexical e sintático; a dimensão textual, do módulo hierárquico; e a dimensão situacional se constitui dos módulos interacional e referencial.

As informações capturadas com essa descrição inicial vão ser combinadas constantemente na constituição e no funcionamento do discurso. E é essa combinação que vai permitir ao analista dar conta da complexidade dos discursos, focalizando as chamadas formas de organização discursiva. O MAM propõe dois tipos de formas de organização: as elementares (fono-prosódica, semântica, relacional, informacional, enunciativa, sequencial, operacional) e as complexas (periódica, tópica, polifônica, composicional, estratégica). As formas de organização elementares resultam da combinação de informações provenientes apenas dos módulos. Já as formas de organização complexas combinam informações extraídas dos módulos e das formas de organização elementares e/ou complexas (ROULET, 1999, ROULET, FILLIETTAZ, GROBET, 2001, MARINHO, 2004, CUNHA, 2013).

Para verificar a hipótese de que a expressão na verdade pode atuar como marca de discurso implicitado, deve-se descrever a forma de organização complexa polifônica de produções 
discursivas em que essa expressão ocorre. Essa forma de organização trata das funções dos segmentos de discursos representados. Para isso, ela parte do estudo da organização elementar enunciativa, que descreve as formas desses segmentos de discursos representados. $\mathrm{Na}$ organização complexa polifônica, o estudo das funções que essas formas exercem se faz por meio da combinação da análise enunciativa com informações extraídas da análise de outros módulos e formas de organização do discurso.

Neste trabalho, estudamos quatro ocorrências da expressão na verdade. Duas foram extraídas de um artigo de opinião, e duas, de um debate eleitoral. O artigo de opinião intitula-se Algo de errado e foi publicado na revista Veja. Já o debate foi promovido pela Rede Globo, no segundo turno das eleições para a prefeitura de São Paulo, em 2012, e foi protagonizado pelos então candidatos Fernando Haddad (PT) e José Serra (PSDB). A análise dessas duas produções discursivas permitirá evidenciar que a expressão na verdade pode atuar como marca de discurso implicitado em exemplares tanto de gêneros monologais, como o artigo, quanto de gêneros dialogais, como o debate.

Seguindo o método proposto pelo MAM, a descrição da forma de organização complexa polifônica dessas produções discursivas é feita em três etapas. Inicialmente, descrevemos a forma de organização enunciativa do artigo de opinião e do debate eleitoral, para mostrar que os segmentos articulados pelas ocorrências de na verdade representam os discursos de diferentes instâncias enunciativas. Em seguida, estudamos a forma de organização relacional, para verificar qual relação de discurso a expressão na verdade sinaliza. Por fim, combinamos os resultados das duas primeiras etapas no interior da forma de organização polifônica, pois apenas essa combinação permite compreender o papel que essa expressão, enquanto marca de discurso implicitado, pode exercer na maneira como o locutor representa as vozes de outras instâncias enunciativas em seu discurso.

\section{A representação do discurso alheio: estudo da forma de organização enunciativa}

A forma de organização enunciativa resulta da combinação de informações dos módulos interacional, referencial, sintático e lexical. Essa forma de organização distingue os discursos produzidos dos discursos representados e define os tipos de discurso representado, bem como as formas dos discursos representados na superfície textual.

A distinção entre os discursos produzidos e os representados se faz com base em informações do módulo interacional. Em linhas gerais, esse módulo trata da materialidade interacional. O estudo dessa materialidade se faz por meio da articulação de três parâmetros: 1) canal (oral, escrito, visual); 2) modo (co-presença e distância espacial e temporal); 3) tipo de vínculo (existência ou não de reciprocidade entre os interactantes) (ROULET, FILLIETTAZ, GROBET, 2001).

O enquadre que resulta da análise desse módulo evidencia que uma situação de comunicação pode se caracterizar pela ocorrência simultânea de diferentes níveis de embotamento interacional. A materialidade interacional dos exemplares dos gêneros artigo de opinião e debate, gêneros a que pertencem os discursos analisados neste trabalho, pode ser descrita por meio de um enquadre de três níveis interacionais. Tanto o articulista quanto os candidatos podem representar personagens interagindo. A interação entre personagens se dá em um nível interno em relação ao nível em que interagem o articulista e seus leitores, no artigo de opinião, e os candidatos, no debate. Por sua vez, essa interação é encaixada em uma interação de nível mais externo entre a instância midiática (jornal ou revista para o artigo e emissora de televisão para o debate) e a instância de recepção (o leitorado para o artigo ou os telespectadores para o debate).

Mas, apesar da semelhança de um enquadre de três níveis, os parâmetros de cada situação de comunicação são sensivelmente diferentes no nível intermediário, o que tem impacto profundo na organização do discurso e na maneira como os 
interactantes desenvolvem a interação. No debate, o canal oral, a co-presença espacial e temporal e a reciprocidade que caracterizam a interação entre os adversários políticos fazem com que eles possam, a todo momento, retomar, repetir, contestar, reformular a fala do adversário. Já no artigo, o articulista e o leitor estão impedidos de realizar essas mesmas ações, em função dos parâmetros característicos de sua interação, a saber, canal escrito, distância espacial e temporal, e não-reciprocidade. Como veremos, essas propriedades materiais são relevantes para entender o papel da expressão na verdade em cada situação de comunicação. Por motivo de espaço, representamos a materialidade interacional das duas situações de comunicação por meio de um mesmo enquadre (Figura 1).
Com as informações do módulo interacional, o MAM define também três tipos de discurso representado: diafônico, polifônico e autofônico. É diafônico o segmento em que o locutor representa o discurso de seu interlocutor direto, aquele com quem compartilha o mesmo nível interacional (Você disse $X)$. É polifônico o segmento em que o locutor representa o discurso de instâncias situadas em outros níveis interacionais, como, por exemplo, o discurso de personagens (Ela/Ele disse $X$ ). Por fim, é autofônico o segmento em que o locutor representa seu próprio discurso ( $E$ u disse X) (ROULET, 1997; ROULET; FILLIETTAZ; GROBET, 2001).

Combinando informações dos módulos lexical, sintático e referencial, a forma de organização enunciativa define ainda as formas dos tipos de discurso (diafônico, polifônico e autofônico). Do ponto

\begin{tabular}{|c|c|c|c|c|c|}
\hline $\begin{array}{l}\text { instancia: } \\
\text { de producto }\end{array}$ & $\begin{array}{l}\text { Arvigo: } \\
\text { escrito } \\
\text { distância es } \\
\text { nåo-recipro }\end{array}$ & $\begin{array}{l}\text { intariocutor } \\
\text { ocal } \\
\text { copressencenag } \\
\text { teciprocida } \\
\text { aco-temporal } \\
\text { dade }\end{array}$ & $\begin{array}{l}\text { interlocutar } \\
\text { espaço-temporal } \\
\text { de } \\
\text { Debato: } \\
\text { oral } \\
\text { co-presencha espacotern } \\
\text { reoprocidade }\end{array}$ & $\begin{array}{l}\text { jeitool } \\
\text { locutor }\end{array}$ & $\begin{array}{c}\text { instância } \\
\text { de recepcăo }\end{array}$ \\
\hline \multicolumn{2}{|c|}{$\begin{array}{l}\text { Artigo: } \\
\text { escrito } \\
\text { distáncia espaço temporal } \\
\text { nắ-recopocidade. }\end{array}$} & \multicolumn{3}{|c|}{$\begin{array}{l}\text { Debate: } \\
\text { cral } \\
\text { distanca espacial e co-presença temporal } \\
\text { nảo-reciprocidade }\end{array}$} & \\
\hline
\end{tabular}

Figura 1: enquadre interacional.

Com base em informações do módulo interacional, define-se o discurso produzido como aquele cujos responsáveis são as instâncias que ocupam o nível interacional mais externo ou elevado do enquadre. No artigo e no debate, o discurso produzido por uma personagem torna-se discurso representado no discurso produzido pelo autor do artigo ou pelo candidato a um cargo público. Da mesma forma, o discurso produzido pelo autor e pelo candidato torna-se discurso representado, ao ser divulgado por uma organização midiática (jornal/revista e emissora de televisão, respectivamente). protestar, discutir) ou por uma nominalização (reclamação, protesto, discussão).

b) O discurso representado pode ser formulado, 0 que pode ser feito nas formas tradicionais dos discursos direto, indireto ou indireto livre.

c) O discurso representado pode ser implicitado por um conector. Nesse caso, o conector liga o discurso produzido pelo locutor na retomada implícita de discurso produzido por outra instância enunciativa, que pode ser o interlocutor ou uma personagem. 
Como exposto na introdução, este trabalho busca verificar a hipótese de que a expressão conectiva na verdade pode atuar como marca de discurso implicitado. Para isso, estudamos o papel dessa expressão na forma de organização polifônica de um artigo de opinião e de um debate eleitoral. Como nosso objetivo é entender o funcionamento dessa expressão, a análise da forma de organização enunciativa das duas produções discursivas focalizará apenas os segmentos de discursos representados articulados por na verdade. Como informado, o artigo de opinião se intitula Algo de errado e foi publicado na revista Veja, na edição de 27 de abril de 2011. Nesse artigo, reproduzido a seguir, há duas ocorrências de na verdade. A numeração indica a segmentação do texto em atos, a unidade mínima de análise do MAM.

(01) Além da morte e dos impostos, (02) como é o caso para o resto da humanidade, (03) existe no Brasil uma terceira grande certeza: (04) obras públicas jamais são entregues no prazo. (05) Também podem não ser entregues nunca; (06) é comum que, (07) uma vez concluídas, (08) estejam entre as de pior qualidade que a engenharia mundial consegue produzir (09) e sempre, em todos os casos, acabam custando muito mais caro do que deveriam. (10) Mas é o atraso na entrega, sem dúvida, a marca que mais distingue as obras públicas brasileiras de quaisquer outras. (11) Na verdade, nenhum cidadão deste país acredita que alguma coisa feita pelo governo possa ficar pronta no prazo - (12) do trembala ao mais reles abrigo para um ponto de ônibus. ((13) Esse trem bala, aliás, promete. (14) Ainda não foi colocado um único metro de trilho no chão, (15) mas o preço estimado da obra já passou de 18 para 33 bilhões de reais.) (16) Nada mais natural, assim, do que 0 anúncio segundo 0 qual não serão terminadas a tempo as majestosas obras de nove dos treze aeroportos que servem a cidades-sedes da Copa do Mundo de 2014. (17) A novidade, no caso, é que o aviso vem de um órgão do próprio governo, o Instituto de Pesquisa Econômica Aplicada (IPEA). [...] (28) Sua avaliação sobre o andamento das obras nos aeroportos é severa. [...](35) Nem metade das verbas destinadas aos aeroportos entre 2003 e 2010 foi realmente aplicada. (36) O governo, na verdade, tem se mostrado incapaz de executar 0 próprio orçamento. (37) O resultado é que até este primeiro trimestre de 2011 se aplicou apenas $0,25 \%$ do que os PAC 1 e 2 previam que seria aplicado: (38) neste ritmo, (39) conseguiremos atingir no fim do ano a grande marca de $1 \%$ do que deveria ser feito.

Na primeira ocorrência de na verdade, os atos (10) e (11), articulados pela expressão, representam as vozes de instâncias enunciativas distintas. No ato
(10) (Mas é o atraso na entrega, sem dúvida, a marca que mais distingue as obras públicas brasileiras de quaisquer outras), o operador sem dúvida evidencia a tentativa do autor de fazer o leitor crer que a informação expressa no ato seria de conhecimento geral, embora seja calcada na visão de mundo particular de um segmento social e profissional muito específico (os jornalistas e articulistas da revista Veja). Portanto, o autor busca identificar a voz que representa com a voz popular ou o senso comum. No ato (11) (nenhum cidadão deste país acredita que alguma coisa feita pelo governo possa ficar pronta no prazo), o autor representa a voz de uma instância agora explicitamente mencionada, os cidadãos, tentando fazer crer que todo cidadão pensa dessa forma.

Na segunda ocorrência de na verdade, os atos articulados pela expressão também representam as vozes de instâncias enunciativas diferentes. No ato (35) (Nem metade das verbas destinadas aos aeroportos entre 2003 e 2010 foi realmente aplicada), o autor representa a voz do IPEA, órgão do governo que, segundo o articulista no ato (17), forneceu os dados expressos no ato (35). $O$ ato (36) (O governo, na verdade, tem se mostrado incapaz de executar 0 próprio orçamento) constitui um segmento de discurso produzido, porque nele o autor apresenta sua própria voz ou uma interpretação particular dos dados supostamente divulgados pelo IPEA.

Descritas as vozes articuladas pelas ocorrências da expressão na verdade no artigo, realizamos a mesma descrição no debate eleitoral. Como exposto, o debate foi promovido pela Rede Globo, no dia 26 de outubro de 2012, e foi protagonizado pelos então candidatos à prefeitura de São Paulo, Fernando Haddad (PT) e José Serra $(\mathrm{PSDB})^{1}$. Esse debate também apresenta duas ocorrências da expressão na verdade. Em função dos nossos objetivos, apresentamos apenas os trechos

\footnotetext{
${ }^{1}$ A transcrição do debate foi publicada pelo jornal Folha de $S$. Paulo, no dia 27 de outubro de 2012. A análise recai sobre essa transcrição. O debate completo pode ser acessado em: $<$ http://www1.folha.uol.com.br/poder/1176189-leia-a-transcricaodo-debate-da-tv-globo-entre-candidatos-a-prefeito-de-sp.shtml>. Acesso em: 02/03/2014. Esse debate foi objeto de análise mais detalhada em Cunha (2015).
} 
em que ocorrem as expressões. A primeira ocorrência encontra-se na fala de José Serra.

Mediador César Tralli: O tema é corrupção. Candidato, o senhor tem trinta segundos para formular a pergunta.

José Serra: (01) Olha, hoje quando se fala em corrupção, (02) a lembrança imediata é o mensalão. (03) Na verdade, a cúpula do PT foi considerada culpada de desvio de dinheiro público. (04) Para compra de votos. (05) Mais do que isso, foi julgada e condenada. Condenada a prisão. (06) Eu queria que você explicasse, Fernando Haddad, aos paulistanos, por que isso aconteceu. (07) Como é mesmo, de que maneira isso ocorreu em Brasília com o PT?

Por meio dos atos (01) e (02), o candidato se vale de recurso semelhante ao usado pelo articulista na primeira ocorrência de na verdade no artigo de opinião. Ao dizer quando se fala em corrupção, o candidato representa a voz do senso comum, indicada pelo se impessoal, na tentativa de fazer os telespectadores (eleitores) crerem que é de amplo conhecimento a relação entre corrupção e mensalão ${ }^{2}$. Nos atos (03) a (05), introduzidos por na verdade, infere-se que o candidato representa a voz da justiça, por fazer menção a julgamentos e condenações. Porém, o candidato não explicita a instância enunciativa responsável pelas informações, porque usa a voz passiva sem o agente da passiva (a cúpula do PT foi considerada $\varnothing$ culpada de desvio de dinheiro público).

Nesse mesmo debate, a segunda ocorrência da expressão na verdade encontra-se na fala de Fernando Haddad.

José Serra: (01) Fernando, preliminarmente eu permito dizer que você está muito nervoso, muito agressivo, (02) eu acho que isso não ajuda a qualidade do nosso debate, com toda a franqueza. (...)

Fernando Haddad: (01) Serra, na verdade o que você nota de nervosismo é indignação, (02) eu corri essa cidade inteira (03) e eu passei pelos bairros mais pobres dessa cidade, (04) não sei se você foi ao

\footnotetext{
${ }^{2}$ Vale observar que, num debate, embora o interlocutor imediato de um candidato seja o adversário (como evidenciam as perguntas e os vocativos), a "razão de ser" do diálogo entre eles é o telespectador com quem a emissora de televisão interage no nível mais externo do enquadre interacional e para quem promove o debate (cf. Figura 1).
}

jardim Peri, (05) eu não sei se você foi a Vila Bela, (06) eu não sei se você está acompanhando o que está acontecendo na Cidade de São Paulo. (...)

Nessa ocorrência de na verdade, Haddad também articula diferentes vozes por meio da expressão. Porém, diferentemente das três ocorrências estudadas anteriormente, essa ocorrência não é antecedida de um segmento de discurso representado, em que Haddad representaria a voz de outra instância, a de seu adversário. Ao contrário, a informação em que o conector se liga tem origem nos atos iniciais da própria fala de Serra ((01) Fernando, preliminarmente eu permito dizer que você está muito nervoso, muito agressivo (...)). A maneira como Haddad procede à articulação da intervenção introduzida por na verdade e dessa informação com origem na parte inicial da fala do adversário será estudada no próximo item, na descrição da forma de organização relacional.

Com relação aos tipos de discursos (diafônico, polifônico e autofônico), as duas ocorrências da expressão na verdade no artigo e a ocorrência dessa expressão na fala de Serra articulam segmentos de discursos polifônicos, ou seja, representam discursos de personagens, que são as instâncias localizadas no nível de interação mais interno do enquadre interacional (Figura 1). Apenas a ocorrência de na verdade na fala de Haddad articula segmentos de discursos diafônicos, porque representam a fala do interlocutor imediato ou de seu adversário político.

No próximo item, investigamos o papel das ocorrências de na verdade na articulação textual.

\section{A articulação textual: estudo da forma de organização relacional}

No MAM, as relações de discurso e o papel dos conectores na sinalização ou na determinação dessas relações são estudados na forma de organização relacional (OR). A descrição da OR se faz em duas etapas. A primeira se baseia na acoplagem entre (1) informações obtidas com a análise do texto do ponto de vista da dimensão hierárquica (informações relativas à definição dos 
constituintes textuais e às relações de dependência, independência e interdependência entre os constituintes), e (2) informações de ordem lexical e sintática, relativas às instruções dadas pelos conectores presentes nos textos (ou que neles possam ser inseridos para a explicitação da relação textual). Com a análise dessa primeira etapa, torna-se possível a proposição de uma estrutura hierárquicorelacional para o texto, por meio da qual se descrevem as relações interativas genéricas entre os constituintes textuais e informações da memória discursiva. A memória discursiva é definida como o "conjunto de saberes conscientemente partilhados pelos interlocutores" (BERRENDONNER, 1983, p. 230).

Essa primeira etapa de análise da OR do texto poderá ser completada, na segunda etapa, com a descrição das relações discursivas específicas. Essa descrição é feita com a aplicação de um princípio geral de cálculo inferencial, em função das propriedades linguísticas e contextuais de enunciados ou segmentos extraídos do texto, e das propriedades inferenciais dos conectores, que oferecem instruções sobre como tratar as informações por eles ligadas e sobre as implicações contextuais inferíveis dos segmentos linguísticos em que se encontram.

$\mathrm{Na}$ primeira etapa da análise, distinguem-se dois tipos de relações textuais na OR dos textos: as relações ilocucionárias (ou dialogais) e as interativas (ou monologais) (ROULET, 2006). As relações ilocucionárias concernem aos constituintes de uma troca - maior unidade dialogal -, enquanto as interativas dizem respeito aos constituintes da intervenção - maior unidade monologal. Essas relações são definidas em um número reduzido de relações genéricas. A hipótese é a de que é possível definir um número restrito de relações, fundamentando-se em operações básicas requeridas para o alcance da completude dialógica, a qual estabelece que uma troca chega a seu fim quando os interlocutores alcançam o duplo acordo e finalizam o processo de negociação discursiva, e da completude monológica, a qual estabelece que cada intervenção que constitui uma troca deve prover informação suficientemente relevante de modo a funcionar como contribuição adequada para o processo de negociação discursiva.

Assim, o MAM define dez relações genéricas para a descrição de todas as formas de discurso, uma vez que cada categoria genérica recobre diferentes relações, como, por exemplo, a relação de argumento, que abrange as relações denominadas de causa, explicação, justificação, consequência, condição, finalidade, evidência, propósito etc. No nível da troca, definem-se as relações ilocucionárias (1) iniciativas e (2) reativas. No nível da intervenção, definem-se as relações interativas de (1) argumento, (2) contra-argumento,

(3) reformulação, comentário, (5) topicalização, (6) sucessão, (7) preparação e (8) clarificação (ROULET; FILLIETTAZ; GROBET, 2001).

Conforme demonstrado por Mendes (2015) e Marinho (2016), a expressão na verdade sinaliza uma relação de reformulação, sendo, portanto, uma expressão conectiva reformulativa. Os conectores reformulativos são suscetíveis de apresentar o constituinte textual que introduzem como sendo uma reconsideração da informação previamente estocada na memória discursiva à qual remetem. Eles criam uma relação que não existia antes, mas que passa a existir com seu emprego nos textos (diferentemente do que fazem os conectores argumentativos, que não criam necessariamente uma relação que não existia antes).

Os conectores reformulativos promovem uma retrointerpretação de informações previamente estocadas na memória discursiva. A reformulação traz uma modificação quanto à forma e quanto à maneira como o locutor apreende a realidade evocada num constituinte textual anterior. A retrointerpretação causada por um conector reformulativo pode também se reportar a uma informação que não tinha sido explicitada ainda. Assim, o uso do conector permite ao locutor indicar explicitamente a mudança de perspectiva operada.

Tratando especificamente da expressão na verdade, entendemos que ela funciona, nas quatro ocorrências estudadas no item anterior, como uma 
expressão conectiva de reformulação, porque, por meio dessa expressão, tanto o autor do artigo quanto os candidatos no debate apresentam uma nova formulação de informações da memória discursiva com origem em constituinte ou constituintes textuais anteriores, com o intuito de explicar, reforçar, recapitular, retificar ou mesmo negar essas informações. Por motivo de espaço, vamos descrever o funcionamento de duas das quatro ocorrências estudadas, uma do artigo e uma do debate. Com o trecho a seguir, reproduzimos a primeira ocorrência de na verdade no artigo de opinião.

(10) Mas é o atraso na entrega, sem dúvida, a marca que mais distingue as obras públicas brasileiras de quaisquer outras. (11) Na verdade, nenhum cidadão deste país acredita que alguma coisa feita pelo governo possa ficar pronta no prazo.

Ao dizer (11) Na verdade, nenhum cidadão deste país acredita que alguma coisa feita pelo governo possa ficar pronta no prazo, o autor do artigo retoma e reforça a ideia defendida no ato (10) de que as obras públicas no Brasil jamais são entregues no prazo. E, ao mesmo tempo, ele impõe ao leitor uma mudança de perspectiva, apresentando sua formulação como mais conforme aos fatos ou à realidade do que apresentou anteriormente. Em (11), ele explicita que nenhum cidadão deste país acredita que qualquer coisa feita pelo governo possa ficar pronta no prazo. Nessa reformulação, fica claro que os leitores a quem o autor se dirige e de quem espera adesão são os cidadãos deste país. É com eles que o autor estabelece um processo de negociação. Nesse sentido, com o emprego de na verdade, evidencia-se uma manobra realizada pelo autor para persuadir 0 leitor. Essa interpretação pode ser visualizada nesta estrutura hierárquica (Figura 2). (Intervenção = I; ato $=A$; principal $=p$; subordinado $=\mathrm{s}$; reformulação $=$ ref.)

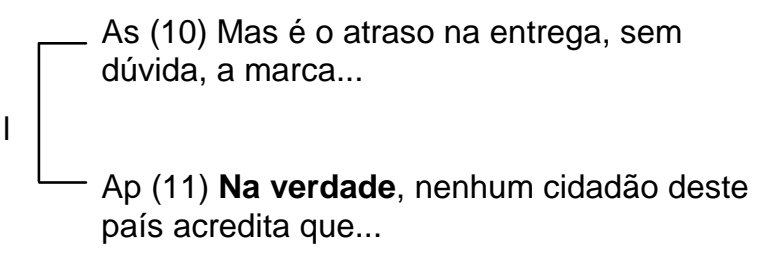
ref
Já no trecho a seguir, em que se encontra a segunda ocorrência da expressão na verdade no debate, a qual foi empregada por Haddad, o candidato faz uso dela ligando o constituinte textual formado pelos atos (01) a (05) a uma informação da memória discursiva cuja origem não está nos atos finais da intervenção previamente produzida pelo adversário.

José Serra: (01) Fernando, preliminarmente eu permito dizer que você está muito nervoso, muito agressivo, (02) eu acho que isso não ajuda a qualidade do nosso debate, com toda a franqueza. (...)

Fernando Haddad: (01) Serra, na verdade o que você nota de nervosismo é indignação, (02) eu corri essa cidade inteira (03) e eu passei pelos bairros mais pobres dessa cidade, (04) não sei se você foi ao jardim Peri, (05) eu não sei se você foi a Vila Bela, (06) eu não sei se você está acompanhando o que está acontecendo na Cidade de São Paulo. (...)

$\mathrm{Na}$ intervenção de Serra, logo após acusar Haddad de estar muito nervoso e agressivo, nos atos (01) e (02), ele passa a tratar de moradia ((03) Agora, na questão da moradia, como eu disse, (04) já disse muitas vezes, (05) nós fizemos 28 mil moradias (...)). Em sua resposta, Haddad utiliza a expressão na verdade para articular a intervenção (01) a (05) a informações ativadas na memória discursiva que tiveram origem na intervenção de Serra, para mostrar sua não aceitação da acusação de que estaria nervoso e agressivo e promover, desse modo, uma mudança de perspectiva em relação à fala do adversário.

Estudando a expressão conectiva reformulativa en fait, Roulet (2003) observa que expressões conectivas de natureza adverbial podem articular o segmento que introduzem a uma informação da memória discursiva cuja origem não é o segmento textual imediatamente anterior. Segundo o autor, essa seria, inclusive, uma diferença entre conectores formados por advérbios ou expressões adverbiais e conectores formados por conjunções, já que estas, a exemplo do porque e do pois, ligariam o segmento que introduzem a uma informação com origem no segmento imediatamente anterior.

Figura 2: estrutura hierárquica (artigo). 
Essa análise se aplica à ocorrência em estudo da expressão na verdade. De fato, como exposto, com o uso dessa expressão de natureza adverbial, Haddad liga o constituinte que ela introduz a uma informação que supõe estar presente na memória discursiva dos interlocutores, embora sua origem esteja mais na parte inicial da intervenção precedente do adversário. Com base em Roulet (2003, p. 160), representamos essa interpretação da seguinte forma (Figura 3). (Troca $=\mathrm{T}$; intervenção $=\mathrm{I}$; memória discursiva $=\mathrm{M}$; iniciativa $=\mathrm{in}$; reativa $=$ re; reformulação = ref.)

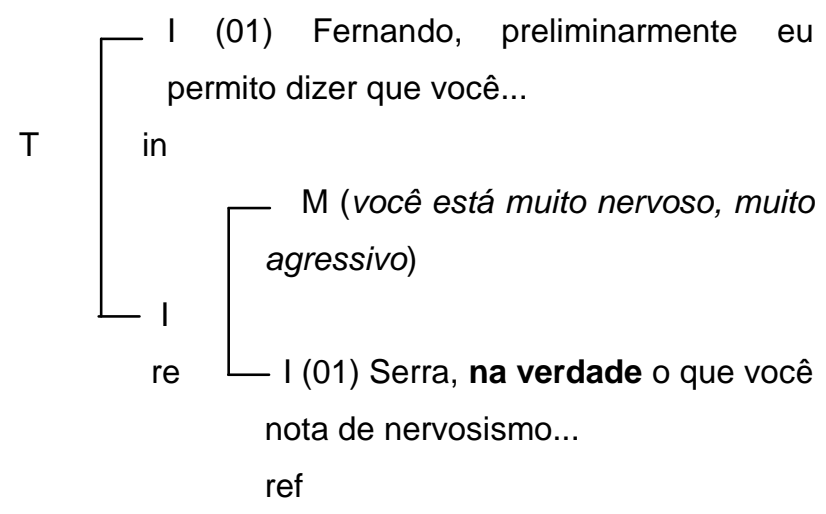

Figura 3: estrutura hierárquica (debate).

Nessa estrutura, a intervenção produzida por Haddad e encabeçada pela expressão na verdade se liga a uma informação da memória discursiva (M) com origem na parte inicial da intervenção do adversário. Por meio dessa expressão, ocorre uma substituição, ou seja, uma supressão da informação estacada em $M$, seguida de uma nova atualização: a indignação de Haddad substitui o nervosismo.

A análise relacional das ocorrências da expressão conectiva na verdade mostra que essa expressão marca uma relação de reformulação, porque impõe uma releitura de informação com origem em um constituinte textual previamente elaborado. Sendo assim, do ponto de vista relacional, na verdade opera uma revisão do que foi enunciado antes, embora não suprima ou apague a informação anterior. Com essa expressão, o locutor/autor indica que procede a uma recapitulação da informação previamente enunciada, para atualizá-la, contestá-la, reforçá-la ou extrair dela o essencial.

No próximo item, procedemos ao estudo da forma de organização polifônica dos segmentos do artigo e do debate em que ocorre a expressão na verdade. Esse estudo é feito por meio da acoplagem das análises realizadas no item anterior, sobre a forma de organização enunciativa, e neste item, sobre a forma de organização relacional. Com esse estudo, buscamos mostrar a atuação da expressão na verdade como marca de discurso implicitado.

\section{A expressão na verdade como marca de discurso implicitado: estudo da forma de organização polifônica}

Tanto no artigo de opinião quanto no debate eleitoral estudados, o produtor do discurso emprega a expressão conectiva na verdade para articular segmentos que representam as vozes de diferentes instâncias enunciativas (a justiça, o senso comum, o IPEA, o adversário político) e segmentos de discursos produzidos, ou seja, segmentos cuja instância enunciativa responsável é o próprio produtor do discurso. Nesse sentido, nas quatro ocorrências analisadas, o produtor do discurso emprega a expressão na verdade não apenas para conectar o constituinte textual que introduz a uma informação previamente estocada na memória discursiva, mas também para proceder a uma revisão ou retrointerpretação de um segmento de discurso que representa a voz de outra instância discursiva. Dessa forma, a combinação de informações enunciativas e relacionais revela que, nas quatro ocorrências de na verdade, essa expressão funciona como marca de discurso implicitado.

Partindo dessa constatação geral, é preciso considerar o tipo de discurso representado que a expressão na verdade retoma (diafônico, polifônico e autofônico), para especificar melhor o funcionamento dessa expressão como marca de discurso implicitado e, assim, entender as funções que na verdade pode exercer na forma organização polifônica de uma produção discursiva. 
No MAM, foram estudadas especialmente ocorrências de discurso implicitado em cartas e em diálogos face a face (ROULET, 1997; ROULET et al, 1985). Nas cartas, por meio de um conector, o autor liga um constituinte textual da carta que escreve a informações da memória discursiva que têm origem em carta previamente recebida. De forma semelhante, no diálogo face a face, com o auxílio de um conector, o locutor encadeia um constituinte textual da intervenção que produz em informações da memória discursiva com origem em intervenção produzida anteriormente pelo interlocutor. Tanto na carta quanto no diálogo face a face, o objetivo é subordinar o discurso representado ao discurso produzido, rejeitando, desvalorizando ou pondo em dúvida o discurso do interlocutor imediato. Por isso, em ambos os casos, trata-se de discursos implicitados diafônicos, já que o locutor retoma implicitamente o discurso produzido pelo interlocutor direto, aquele com quem compartilha o mesmo nível interacional (Figura 1), e não por um personagem.

Neste trabalho, as ocorrências de na verdade que estudamos mostram que uma marca de discurso implicitado possibilita ao produtor do discurso retomar implicitamente o discurso produzido não só pelo interlocutor direto, mas também por um personagem ou por uma instância enunciativa localizada no nível de interação mais interno do enquadre interacional. Das quatro ocorrências analisadas, apenas a que se encontra na fala de Haddad é empregada na retomada do discurso do interlocutor imediato, ou seja, apenas essa ocorrência é diafônica. As outras três ocorrências são polifônicas, porque usadas para retomar o discurso produzido por personagens. Para exemplificar, vejamos novamente a segunda ocorrência de na verdade no artigo de opinião.

(35) Nem metade das verbas destinadas aos aeroportos entre 2003 e 2010 foi realmente aplicada. (36) O governo, na verdade, tem se mostrado incapaz de executar o próprio orçamento.

Com a expressão na verdade, o autor retoma um segmento (o ato 35) em que representa a voz do IPEA, órgão do governo que, segundo o articulista, forneceu os dados mencionados, subordinando-o a um segmento de discurso produzido, que é o ato (36). Assim, com a expressão na verdade, o autor retoma não o discurso de seu interlocutor imediato, o leitor do artigo, mas de outra instância enunciativa, o IPEA, situada no nível interacional mais interno do enquadre interacional. A análise dessa ocorrência demonstra, portanto, que uma marca de discurso implicitado, como a expressão na verdade, pode retomar não só o discurso do interlocutor imediato (implicitado diafônico), mas também o discurso de outras instâncias enunciativas situadas em outros níveis interacionais (implicitado polifônico).

A percepção da existência desses dois tipos de discurso implicitado (o diafônico e o polifônico) permite levantar algumas hipóteses sobre as funções que a expressão na verdade exerce quando atua ou como marca de discurso implicitado diafônico e ou como marca de discurso implicitado polifônico.

Quando a expressão na verdade funciona como marca de discurso implicitado polifônico, sua função parece ser a de conferir maior sustentação para a informação que a expressão introduz, na busca por fazer com que o interlocutor imediato aceite mais facilmente essa informação. Nesse caso, ao usar uma marca de discurso implicitado polifônico, o que se busca é principalmente reforçar, esclarecer e usar como apoio (e não rejeitar) a informação dada, conquistando a adesão do leitor ou ouvinte.

Na ocorrência estudada anteriormente, em que na verdade é marca de discurso implicitado polifônico, o emprego da expressão constitui importante recurso argumentativo, uma vez que permite ao articulista, ao mesmo tempo, mostrar ao leitor que a incapacidade do governo é atestada por um instituto do próprio governo, o IPEA, e apresentar o discurso que produz, no ato (36), como uma retrointerpretação fundamental dos dados do instituto, por ser esse ato um constituinte principal em relação ao ato (35).

Porém, quando a mesma expressão na verdade funciona como marca de discurso implicitado diafônico, articulando o constituinte que introduz a uma informação da memória discursiva com origem na fala do interlocutor imediato, ocupante do mesmo nível interacional, ela atua como um recurso 
importante para atacar, rejeitar ou desvalorizar o discurso do interlocutor imediato. Essa é a função que caracteriza as ocorrências de discursos implicitados estudadas no MAM em cartas e diálogos face a face. É também a função que exerce a expressão na verdade na fala de Haddad, única das quatro ocorrências por nós estudadas em que o produtor do discurso usa essa expressão para retomar a fala do interlocutor imediato. Como verificamos ao longo deste trabalho, Serra acusa Haddad de estar nervoso e agressivo, acusação que Haddad rejeita e modifica. Embora marcas de discurso implicitado diafônico tenham sido atestadas em cartas (ROULET et al, 1985), é provável que seu uso seja mais comum em situações cuja materialidade interacional se caracteriza por canal oral, co-presença espacial e temporal e reciprocidade, como bate-papos e debates.

Nessa perspectiva, cabe observar que, quando um conector é usado como marca de discurso implicitado diafônico, ele exerce um papel importante não só na forma de organização polifônica, mas também na forma de organização estratégica, tal como apontado por Roulet (1997, ROULET, FILLIETTAZ, GROBET, 2001). A forma de organização estratégica trata das relações de faces e lugares entre os interactantes (ROULET, FILLIETTAZ, GROBET, 2001). Tomando a fala de Haddad como exemplo, verificamos que, ao usar a expressão na verdade para retomar o discurso de Serra, Haddad busca não só rejeitar a pertinência do comentário feito pelo adversário (Fernando, preliminarmente eu permito dizer que você está muito nervoso, muito agressivo), mas ainda atacar sua face, apresentando-o como um gestor público insensível e incapaz de entender os problemas da cidade ((01) Serra, na verdade o que você nota de nervosismo é indignação, (02) eu corri essa cidade inteira (...) (06) eu não sei se você está acompanhando o que está acontecendo na Cidade de São Paulo).

\section{Considerações finais}

Neste trabalho, buscamos contribuir com os estudos que analisaram o papel conectivo da expressão na verdade. Aprofundando esses estudos, mostramos que essa expressão tem um papel importante na maneira como o locutor representa em seu discurso outros discursos ou outras vozes. Ao mesmo tempo, buscamos trazer uma contribuição aos estudos da argumentação que focalizam a natureza polifônica dos conectores.

Mais especificamente, verificamos que a expressão na verdade exibe um funcionamento bastante complexo, cuja compreensão apenas se obtém mediante a combinação de informações lexicais, sintáticas, hierárquicas, interacionais, relacionais e enunciativas no interior da forma de organização polifônica. Ao final de nosso percurso de análise, verificamos que a expressão pode funcionar como marca de discurso implicitado polifônico, ao retomar discursos com origem na voz de personagens, e como marca de discurso implicitado diafônico, ao retomar discursos com origem na voz do interlocutor imediato.

Do ponto de vista das funções que a expressão exerce, quando atua como marca de discurso implicitado polifônico, na verdade reforça a informação dada previamente e geralmente atribuível a uma instância de prestígio (órgão do governo ou justiça), com o fim de conquistar a adesão do leitor ou ouvinte. Mas, quando exerce a função de marca de discurso implicitado diafônico, a mesma expressão funciona como um recurso para atacar, rejeitar ou colocar sob suspeita o discurso do interlocutor imediato, exercendo, portanto, um papel importante na maneira como os interlocutores fazem a gestão das faces envolvidas. Desse modo, o estudo do papel da expressão na verdade na forma de organização estratégica, que estuda a gestão de faces e lugares no discurso, constitui um desenvolvimento possível para a investigação apresentada neste trabalho. 


\section{Referências}

BERRENDONER, A. Connecteurs pragmatiques et anaphore. Cahiers de linguistique française, Genebra, v. 5, p. 215-246, 1983.

CUNHA, G. X. A construção da narrativa em reportagens. 2013. 601 f. Tese (Doutorado em Linguística) - Programa de Pós-Graduação em Estudos Linguísticos, Universidade Federal de Minas Gerais, Belo Horizonte, 2013.

CUNHA, G. X. As relações retóricas e a negociação de faces em debate eleitoral. Confluência, Rio de Janeiro, v. 47, p. 205-238, 2015.

DUCROT, O. O dizer e o dito. Campinas: Pontes, 1987.

DUCROT, O. et al. Les mots du discours. Paris: Minuit, 1980.

MARINHO, J. H. C. Uma abordagem modular e interacionista da organização do discurso. Revista da Anpoll, São Paulo, v. 16, p. 75-100, 2004.

MARINHO, J. H. C. Conexão e argumentação: reflexões sobre o ensino. In: PIRIS, E. L.; OLÍMPIO-FERREIRA, M. (orgs.) Discurso e Argumentação em múltiplos enfoques. Coimbra: Grácio Editor, 2016, p. 151-165.

MENDES, F. T. C. O funcionamento discursivo da expressão na verdade: uma abordagem modular. 2015. 280 f. Tese (Doutorado em Estudos Linguísticos) - Programa de Pós-Graduação em Estudos Linguísticos, Universidade Federal de Minas Gerais, Belo Horizonte, 2015.

ROULET,

E. L'organisationpolyphoniqueetl'organisationinférenti elle d'un dialogue romanesque. Cahiers de linguistiquefrançaise, Genebra, v. 19, p. 149-179, 1997.

ROULET, E. La description de l'organisation du discours : du dialogue au texte. Paris: Didier, 1999.

ROULET, E. Une approche modulaire de la problematique des relations de discours. In: MARI, $\mathrm{H}$. et al. Análise do discurso em perspectivas. Belo Horizonte: FALE/UFMG, 2003, p. 149-178.
ROULET, E.The description of text relation markers in the Geneva model of discourse organization. In: FISCHER, K. (org.). Approaches to discourse particles. Amsterdam: Elsevier, 2006, p. 115-131.

ROULET, E. et al. L'articulation du discours en français contemporain.Berne: Lang, 1985.

ROULET, E.; FILLIETTAZ, L.; GROBET, A. Unmodèle et un instrument d'analyse de l'organisation du discours. Berne: Lang, 2001.

\section{COMO CITAR ESSE ARTIGO}

CUNHA, Gustavo Ximenes; MARINHO, Janice Helena Chaves. A expressão conectiva na verdade: contribuições para uma abordagem polifônica dos conectores reformulativos. Signo, Santa Cruz do Sul, v. 42 , n. 73, jan. 2017. ISSN 1982-2014. Disponível em: <https://online.unisc.br/seer/index.php/signo/article/view/7867>. Acesso em: doi: http://dx.doi.org/10.17058/signo.v42i73.7867. 